\title{
Electronic Education and Libyan Universities
}

\author{
Kolan Al-Kilani \\ Al-Fateh University, Libya
}

saduzo@sbb.rs

\begin{abstract}
Educators continuously are searching for the best methods and means for effective educational surroundings for waking up students' attention for exchange of ideas and experience. Techniques of Information presented in electronic data processing (E.D.P.) and Internet and, in addition to that, techniques from many other means are considered as the most successful means for establishing an educational surrounding that makes possible cooperative plans between different educational institutions and gives possibility for students to develop their experience of interesting subjects through contacts with other students and experts who have the same interests. In this way students are searching for information and for forms of information that have influence on their experience and thinking. Also, contact through the Internet develops their writing skills and experience in English in different fields of subjects and levels.
\end{abstract}

Keywords: electrical education, technology, Internet

\section{Introduction}

Educators continuously are searching for the best methods and means for effective educational surroundings for waking up students' attention for exchange of ideas and experience. Techniques of Information presented in electronic data processing (E.D.P.) and Internet and, in addition to that, techniques from many other means are considered as the most successful means for establishing an educational surrounding that makes possible cooperative plans between different educational institutions and gives possibility for students to develop their experience of interesting subjects through contacts with other students and experts who have the same interests. In this way students are searching for information and for forms of information that have influence on their experience and thinking. Also, contact through the Internet develops their writing skills and experience in English in different fields of subjects and levels.

Also, contacts through the World Wide Net make it possible for teachers to use educational experiences which are unattainable by other ways and make possible connections between persons and between information sources. Using that technology gives a chance for education, in other

Material published as part of this publication, either on-line or in print, is copyrighted by the Informing Science Institute. Permission to make digital or paper copy of part or all of these works for personal or classroom use is granted without fee provided that the copies are not made or distributed for profit or commercial advantage AND that copies 1) bear this notice in full and 2) give the full citation on the first page. It is permissible to abstract these works so long as credit is given. To copy in all other cases or to republish or to post on a server or to redistribute to lists requires specific permission and payment of a fee. Contact HPublisher@InformingScience.orgH to request redistribution permission. words, that is electronic education, privilege of Universities in the future. During last few years, very important changes are registered in the field of education. The business market is opened because of needs for professions and skills and modern specializations in the field of new economy, in accordance with modern requirements and attainable techniques such as electronic education and directly education on Inter- 
net. But, electronic education will be not successful without deep application and introduction into learning systems instead of traditional education, all accompanying with their directly presence at the faculties. Specializations of the institution of electronic education consist of different fields of services, like obtaining of M.A. diploma directly through Internet or issuances of diplomas of technology for two specialized programs in the field of technology of information. Some studies and specialized research indicated that 48 traditional colleges and Universities showed their methods directly by Internet in the year 1998, with increase up to $70 \%$ in the year 2000 , with existence of Universities which do not give services and methods except by Internet such as University Englewood and COLO.

It was expected that industry of directly electronic education through Internet realized more than 6.3 billion US \$ in the year 2002, and more than 23 billions US \$ in the year 2004, according to studies performed by Group EY-DI-SI for market research leaning on great development in the field of electronic business and increase of specialized students. Many companies have projects of appropriate programs also, taking into consideration economy and sciences and renaissance of their countries.

\section{Problem of Study}

Educational institutions today move to radical transformation between economic pressure and large expenses from one side, and business world from other side. Also there is a dispute between students whose choice is presence at the universities and others who want education from distance. They are factors of that transformation. Libya is country which knows only traditional methods of education. It is a country out of new trends in the world of electronic transformations in education, at contrary to intention of Libyan government which claimed development of education and freedom of education and which opened all possibilities for new technology of education under the following title: "Education is not aim for it self, but it is creation of new human being" and which leans on elementary education. The idea from the beginning of the eighties on modernization of universities in Libya and founding of new universities in the last century was not very successful. Periodical published information about teachers shows that there are names of the teachers at the list which are not presented today at faculties. That means that names are given from archives (old archives) and that teachers are not presented from long time ago. There are no lists with names of teachers and members of the faculty boards, even list of departments of any faculty or organization of studies, conditions of entrance examination, programs for each department, as the first step for introduction electronic education into faculties in Libya, like it is reality in many universities in the world. These researchers noticed that there is no consciousness on importance of this kind of education necessary for scientific development, as it is reality in many universities in the world, which introduced this kind of education a long time ago. Contrary to them, at Libyan universities students lose their time in enrollment, entrance examinations, their personal presence during administrative formalities, etc... throngs are big, and all of those facts have negative influence at educational operations. But, implementation of new electronic education will dismiss that and make easy educational services for students and lift level of university education generally. Educational institutions, particularly institutions of high education in progressive world, are directed to using the Internet for enrollment, receiving decisions for students who are located long way off, or students who can not be presented at faculties, some or all of time. In the present time educational Institutions feel economic pressure with establishing of expenses, improvement of quality, answering on pressure of competition and consider that ITInformation Technology is capable to solve those problems, to change role of students and also, faculty. All that gives the necessary time for establishing better teaching methods. With increasing of using of modern technology every faculty or student can adapt to those changes. Scientific degrees are exposed in Internet, students has admissions to enrollment and contacting the Univer- 
sity, can buy books, literature and has admission to trainings without direct physical contact with faculty. This is education through mediation of E.D.P. (Computer). This is also a method for sending students thinking and discussing through Internet without time limits. Participation in this kind of communication gives a chance for students to explain their subjects in free time. Other kind of fast education gives students possibility to discuss in limited time. This transition from traditional education to electronic education is possible to be performed from in traditional education teaching rooms through cyberspace. This is the future of education that is called by electronic education. This study is attempt to answer the following question: why, contrary to the fact that Libya initiated large operation, after the Revolution, with the intention to raise the level of education and to follow world development and that Libya has faculties in far regions, but all of them have traditional educational methods, even Libyan students study in many countries in the World, and they are well informed on modern educational electronic methods, up to now, none of those methods are used in Libyan Universities, like in American and European countries.

This question produces many other questions:

1. What do teachers know about electronic education at Libyan universities?

2. What do students know about electronic education at Libyan universities?

3. What is the main plan for acceptance of electronic education at Libyan universities?

4. What is the interest for electronic education for Libyan society?

5. Which obstacles are in the way of implementation of electronic education at Libyan universities?

\section{Importance of Study}

This study aims to draw attention to the importance of implementation of electronic education at Libyan universities and the solution of many educational problems at Libyan universities and to explain of obstacles in absence of electronic education and also position of society in information epoch and to answer the question what is interest from electronic education and to encourage studies, research, and discussion on that subject for creating a main plan of studies, planning of development of electronic education in Libya.

\section{Limits of Study}

Taking into consideration that this researcher is from Libya and has connection with Libyan university (Al-Fatih University) and that this study opens discussion and possibility of interest, not only in Libya but in Arabic countries and in underdeveloped countries, the study will be concentrated on answers about the questions, without intention to make standard of projecting of electronic education or methods of-electronic education.

\section{What do Teachers know about Electronic Education at Libyan Universities?}

Electronic education is an educational method which uses modern means for contact, using the computer and its net and many means of voice, picture, drawings, means of research, electronic libraries, Internet from distance or in the classroom, use of technology in all its kinds with saving of time and efforts and with the best results (interests). Studying from a distance is part of electronic education. Students receive information from distance from their teacher (as a source of information). When we discuss electronic education, it is not necessary to discuss just express and 
short time limited education (online learning). Electronic education is not limited, location of information source is not important, electronic education is possible through Internet and other intranets. There is also, direct electronic education. Methods and techniques are based on the Internet with the purpose of change of lectures and subjects of researches between teacher and students. In the eighties the CD was used as mean of education, but after that Internet was published as basis for electronic education directly through Internet which made connections between educational institutions. Teachers Council at Al-Fatih University concluded that this technology is characteristic of our epoch and there is a necessity for implementation of new technology in some specializations and at some faculties. But, some members of Teachers Council think that Al-Fatih University is a traditional university and has to stay traditional. It is possible to found a new university with the same name for new experiment at all faculties with electronic control of examinations, diploma issuance, certificates... all actions of education, administration and finance. All that like the experience of open university which has not connection with system of electronic education or with Internet and which is a university which gives service for enrollment, examinations and etc... just like traditional university, and it is necessary to implement new technology into Al-Fatih University with change of methods, from traditional to electronic education through computers, Internet with transformation to electronic education through implementation step by step. Between students in Libya their opinion about electronic education is generally harmonized from the eighties of the last century this is from at that time new experience with open University. But this researcher noticed that there is no connection between open universities and electronic education in which it is possible connection with teachers through Internet by voice, picture or drawings, that means trough electronic Post and giving help by teachers to students. By this way it is possible to obtain the best results for students. It is necessary to open teaching rooms with number of computers connected with Internet what makes possible to all to teach and educate themselves, what traditional faculties can not to give.

\section{What is the Obstacle for Implementation of Electronic Education at Libyan Universities?}

Up to now electronic education is founded at computer CBT (COMPUTER BASED TRAINING), contrary to traditional elemental education. It is possible to implement many technics and methods as in projecting of education and training on the basis of group of methods and technology usable at Libyan Universities. This researcher noticed that two Libyan universities, Al-Fatih University and Kar-Younis University, have an intention to implement electronic education, especially after information issued by the dean of Al-Fatih University for enrollment of 18 students for education from distance at one of British Universities in academic year 2010-2011 as evidence that university has intention to transfer to electronic education as university which has long history and experience and also has good teaching staff in the field of methods and methodology ready to take over the first step for implementation of electronic education. It is a university with 13 faculties with tradition of more than 25 years, and professors received their degrees from American and British colleges (Universities) and also from European Faculties. They are ready to make a program of new electronic education using information. In the same time Libya has more than one center for learning of computer technology, and it is possible to use these centers for preparation of the necessary program and its implementation, control over it, and development and its implementation at Libyan universities. This implementation is not aim for it self, but mean for realization of good results. 


\section{Interest in Electronic Education}

Without any doubt there are interests in this kind of education which are difficult to explain in this study, but it is possible to say that interests in electronic education are:

1. More possibilities for contact between students, between them and universities, possibility of discussions, electronic post, talking rooms, and direct participation of students in exposed subjects.

2. Contribution to different control units for students, like discussion clubs or talking rooms, which give a chance for exchanging opinions about exposed subjects and proposals and comparison with personal opinions coming to the best opinions and experiences through talking rooms.

3. Sense of sameness: equipment for contact are always attainable to students, in contrast to classroom that do not give this privilege and in which it is necessary to organize seats, etc. Using this equipment, a student can deliver his voice through electronic post and discussion clubs and talking rooms. This privilege is a big interest for students who feel fear and trouble because this kind of education gives students chance to express their ideas better than in the classroom of traditional education. Studies showed evidence on that.

4. Easy contact with teacher: electronic education gives possibility of easy contact with teachers and in the shortest time out of officially work time, through electronic post. This is of interest for the teacher who is not obliged to sit in office and does not need to postpone the contact.

5. Possibility of change of learning methods: student can to choose methods, visual or auditory, by different ways through electronic equipment with possibility of change for the methods that are the best way for students.

6. Different educational methods: electronic education makes the possibility for a student to concentrate on important ideas during learning. This helps students because subjects are exposed in a simple and clear way.

7. Additional help from reiteration: reiteration of information makes additional help for students in their preparation during training and preparation for examination.

8. Attainability of programs at any time ( 24 hours daily, 7 days weekly): this is desirable for persons who want to learn at any time in an appropriate time for them: some of them want to learn in the morning, some of them in the night.

9. Continuity of attainability of programs: this privilege makes it possible for students to obtain programs which they want in any time; there is no opening or closing of the library.

10. Independence from physical presence: contrary to traditional education, students are not tied to joint work because modern technology makes possible individual work.

11. Ease and many ways for evaluation of students development: the teacher has many methods to evaluate development of students using fast and easy classifications of information.

12. Rational use of time: rational use of time is a very important element for both sides: teachers and students. Students can obtain information immediately in any time and place; there is no need to go to the classroom or library or professor's office. Time saving is large: professors can save their time and they can send information instantly through direct contact.

13. Electronic education frees teachers from administrative affairs which can take much of their time. Now it is possible to send administrative documents through electronic equipment to students who are informed about those documents. 
14. Reducing of work in the university: electronic education makes possible the analysis of students' marks and results, expertise and statistics, and sending files about students to the faculty registrar.

15. Solution of problem in traditional faculties: electronic education gives a chance of high university education for all, especially for students who are living far away from cities. The problem of traveling disappears with electronic education and, with that, the expenses of students and expenses of state does not exist.

\section{Shortages of Implementation of Electronic Education at Libyan Universities}

Electronic education, like all educational methods, has some shortages (obstacles) in its implementation in all countries of the World. Libyan Universities did not try anything to implement this kind of education. This researcher noticed that Libyan universities are not capable to implement it completely but can implement it from inside traditional teaching rooms with installation of educational equipment using computers for transition, from traditional education to training by voice and pictures and transfer of methodic notices to electronic books, encouraging teachers to develop methods and opening of electronic post like the first step of implementation of education from distance through meetings and conferences with purpose of establishing methodology plans and programs for implementation of electronic education. By our opinion Libyan universities have to:

1. Develop standards. Electronic education spreads very quickly and because of that it is necessary to establish standards which are in agreement with USA standards as is Standard Sharable Content Object Reference Model 1.2 (SCORM).

4. Methodology. There is need to take into consideration that some technicians and specialists some times do not take into consideration the interests of users and that has direct influence on the teacher (how he teaches) and on the student (how he learns), because they are technicians not teachers. This results in the need to establish appropriate methodology of teaching and learning. Attacks at main Internet locations have influence on teachers and result in many questions about its influence on electronic education in the future in regard to contents and examinations. That represents a most important obstacle for electronic education.

5. Digital filtering. Some people or institutions can define contact and time. It is necessary to wait their contacts and are those contacts registered or not, does it result any damage. Solution is to put filtering to prohibit contacts or obstacles which are unwanted, such as calls or notices.

6. Adaptation of students to new standards.

7. Control of ways of outfitting of teaching rooms with fast learning equipments and accordance of methods with accepted plans and programs.

8. Attention to teachers. Do they feel that they are not an important factor in teaching (learning) operations any more.

9. Consciousness of society about this kind of education and on withdrawing from it.

\section{Conclusion}

In the last ten years a revolution in applying of electronic education was registered. But up to now in Libya, the use of computers is in the beginning. In regard to the world, every day an increase of applying of computers in that field is registered, from using computers in education to using 
Internet in education with effective results in educational operations. Elementary characteristics are saving of time and less efforts in educational operations. But at Libyan universities this kind of electronic education is in the beginning. Because of this fact it is possible to say that for implementation of electronic education at Libyan universities it is necessary to make the following: invitation to congresses, meetings and discussions about this subject and collecting information about it, international experience in this field, showing all cultural and scientific conventions between Libyan and international universities that are using this kind of education, invitation of all experts in this field to congress and meetings, discussions about studies and examinations, and all other questions important for this field, opening electronic posts as evidence on contacts between students and faculty as a good first step to develop methods usable at Libyan universities through electronic services, opening posts of methods for services at Libyan universities for each teacher as necessary step to teaching, learning and development of experience and other questions:

1. Attainment of consciousness of teachers and society about this kind of education,

2. Contribution of teachers to establishment of this kind of education and their participation in congress and meetings and discussions about the subject.

3. Establishing of appropriate environment for this kind of education, teaching staff, program of necessary contacts helpfully in transfer of this education from other places, etc.

4. Establishing of trainings for students, teachers and administrative workers for more effective using of this kind of education.

\section{Literature}

A1-Mubarak, Ahmad Abdel Aziz. Influence of learning through international net Internet on students at the faculty of pedagogy by technics of education and contacts of "Al-Melek Saud" University, M.A.Study, unpublished, Department of technology and means of education, Riyad

Al-Atyawi Saleh. (2006). Electronic Education and Open University Gazette of Educational Technology, Riyad, Post graduate Studies Faculty, Dept. of educational technology, A1-Melek Saud University

Al-Musa, A., \& Al-Mubarak, A. (2005). Electronic Education and Application tl, Riyad, Rashd Library, Al-Rafai, Omar, (2002) Elctronics Study, knowledge, No.91

Al-abadi, M. (2002). Education and traditional education what is different? Knowledge, No.91

Bahti, I. (2007). Technics, work submitted to University Center, htpp:/www.show.ph/mohammed.com.dros returned 24-4.2007. Ph.D.Hada Al-Jahni Electronic Education and connection with educational tecnics, net

\section{Biography}

Kolan Al-Kilani obtained the Diploma of Arts in 1990 and the first honor of the level of Libya. He obtained the Bachelor of Arts from the University of Al Fateh and the privilege of first installment. Kolan obtained a master's degree from the University of Jabaduchka, Czech Republic. Professor in the Faculty of Arts, Al-Fateh University Libya and Broadcaster Voice of Africa, Tripoli, Libya. He was director general of the Department, Faculty of Arts Registration Libya. He is credited with the introduction of electronic registration and graduation at the Faculty of Arts and chaired the evaluation committees for the school at the level of Libya (2005_2006_2007). 